\title{
Electrosorption for organic pollutants removal and desalination by graphite and activated carbon fiber composite electrodes
}

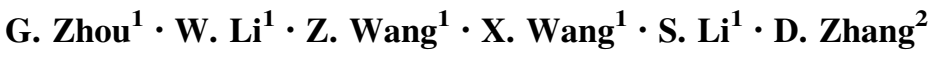

Received: 9 June 2014/Revised: 30 January 2015/Accepted: 18 April 2015/Published online: 1 May 2015

(C) Islamic Azad University (IAU) 2015

\begin{abstract}
This paper investigates a new type of carbonbased electrodes, which were equipped with graphite and activated carbon fiber composite, to improve the performance of electrosorption. The results indicated that the highest desalination efficiency achieved $55 \%$ and the optimal condition was $1.6 \mathrm{~V}$ voltage, $60 \mathrm{~min}$ retention time and $1.0 \mathrm{~cm}$ electrode distance. Freundlich isotherms successfully fitted with the respective behavior of the composite electrode and provided theoretical evidence for the desalination performance improvement. Applied in real black liquor of refined cotton, the graphite and activated carbon fiber composite electrodes achieved high removal efficiency for conductivity $(59 \%)$ and $\mathrm{COD}_{\mathrm{Cr}}(76 \%)$. Similar removal performance was also observed in sodium copper chlorophyll wastewater, and removal efficiency was $37 \%$ for conductivity and $14 \%$ for $\mathrm{COD}_{\mathrm{Cr}}$. For the first time, this research demonstrated the biodegradability improvement in real industrial wastewater via electrosorption treatment, suggesting a potential pretreatment technique for high-salinity wastewater.
\end{abstract}

Electronic supplementary material The online version of this article (doi:10.1007/s13762-015-0811-4) contains supplementary material, which is available to authorized users.

\section{Zhang}

d.zhang@lancaster.ac.uk

1 College of Environment and Safety Engineering, Qingdao University of Science and Technology, Qingdao 266042, People's Republic of China

2 Lancaster Environment Centre, Lancaster University, Lancaster LA1 2YQ, UK
Keywords Electrosorption - Graphite and activated carbon fiber composite electrodes - Saline wastewater . Desalination efficiency

\section{Introduction}

Water pollution is one of the major concerns in water supply and wastewater management (Huang and Xia 2001). Different from domestic wastewater, industrial wastewater aggravated the actuality due to the intensive discharge and threats of toxic compounds, such as heavy metals (Boening 2000), crude oil (Chen et al. 2013; Zhang et al. 2013) and pesticide (Kolpin et al. 2002). It therefore caused serious ecological challenges (Burkholder et al. 2007) and human health risk (Cantor 1997). Particularly, industrial salinity wastewater contained high salt content and was reported with increasing discharge. The intensive attention has been drawn due to its composition of poisonous and hardly decomposed organic pollutants (Lefebvre and Moletta 2006). Since the high salinity damaged the cytomembrane and enzymes of microbes, industrial salinity wastewater inhibited the growth and activities of degrading microorganisms, consequently resulting in the failure of the biological treatment (GuetaDahan et al. 1997). Such challenges have brought difficulties in industrial wastewater treatment plant, raising the practical demand of pretreatment technique of desalination for further biological process.

To achieve effective desalination, many physical and chemical methods have been widely investigated, including thermal dynamic method, chemical method and membrane method (Greenlee et al. 2009; Jing et al. 2009; Mtombeni et al. 2013; Zhao et al. 2011). As a novel method for seawater and industrial wastewater desalination, electrosorption 
has the unique features of low cost, high antipollution ability, environmentally friendly and simple operation (Wang et al. 2012). Trapped by the opposite charge on the electrode surface, the ions in wastewater were adsorbed and fixed in the electrical double layer and subsequently removed from the aqueous phase (Choi and Choi 2010; Nadakatti et al. 2011). Generally, activated carbon (Chang et al. 2011), activated carbon fiber (ACF) (Li et al. 1997), carbon nanotubes ( $\mathrm{Li}$ et al. 2008) and carbon aerogel (Rasines et al. 2012) were the most applied electrode materials. Though carbon aerogel and carbon nanotube had the best desalination performance (Farmer et al. 1995, 1996; Rasines et al. 2012), they suffered from the high cost and were not appropriate for industrial application. Alternatively, surface-modified carbon or carbon-based materials had become the cutting edge for the improvement in electrosorption performance (Ahn et al. 2007; Avraham et al. 2011; Chang et al. 2011; Lee et al. 2009). Since the large specific area and high conductivity are the two key factors affecting electrosorption performance, it is meaningful to develop integral electrode of carbon materials with respective advantages for electrosorption enhancement. Considering the higher electrical conductivity of graphite and the high adsorption efficiency of activated carbon fiber (Ahn et al. 2007; Ishikawa et al. 1996; Jannakoudakis et al. 1993; Kim 2005; Porada et al. 2013b), the integral electrode with the two elements therefore drew many research and industrial interests, viewed as suitable engineering device for practical desalination of industrial salinity wastewater.

In this study, the combination of graphite and activated carbon fiber was applied for desalination and organic pollutants removal as an improved composite electrode material. The determinants affecting the desalting efficiency were analyzed as the operation voltage, initial chloride concentration, $\mathrm{pH}$ value and electrode distance. Applied in real industrial wastewater with high salinity, the graphite and activated carbon fiber composite electrodes had good performance to achieve high removal efficiency of conductivity and improve the biodegradability of the water sample, suggested as a practical pretreatment technique for refined cotton and sodium copper chlorophyll wastewater before further advanced biological treatment.

\section{Materials and methods}

\section{Wastewater sample}

Artificial wastewater and real industrial wastewater samples were investigated in this study. Artificial salinity wastewater contained different level of $\mathrm{NaCl}$ concentration as $100,200,500,1000,2000,5000,10,000$ and $20,000 \mathrm{mg} /$ L. The organic matters were consisted of glucose, and the concentration was from 4000 to $5000 \mathrm{mg} / \mathrm{L}$. The real black liquor of refined cotton wastewater was taken from Shangdong Guangtongbao Pharmaceuticals Co. Ltd. located in Weifang city, China. The sodium copper chlorophyll wastewater was the discharge of Shandong Shengwei Biotech Co. Ltd. located in Heze city, China.

\section{Graphite and activated carbon fiber composite electrodes}

The preparation of graphite and activated carbon fiber composite electrodes followed potassium hydroxide cleaning. Briefly, the graphite and activated carbon fiber $(\mathrm{m}: \mathrm{m}=3: 2)$ were blended as the raw electrode material, subsequently mixed with phenolic resin $(0.25 \mathrm{~g} / \mathrm{mL}$, ethanol as the solvent) with $2: 1$ mass ratio. Afterward, the mixture was pressed and carbonized at 750,850 and $950{ }^{\circ} \mathrm{C}$ for $60 \mathrm{~min}$, respectively, in nitrogen atmosphere. Finally, the composite electrode was treated in boiling $\mathrm{KOH}$ solution $(1 \mathrm{~mol} / \mathrm{L})$ for $3 \mathrm{~h}$, washed by deionized water thoroughly and kept stored in deionized water for further experiment.

\section{Electrosorption desalination device}

The design of electrosorption desalination device is illustrated in Fig. 1. The electrode working voltage was $1.6 \mathrm{~V}$ without specific description, and the influent rate was $10 \mathrm{~mL} / \mathrm{min}$. To evaluate and optimize the desalting and $\mathrm{COD}_{\mathrm{Cr}}$ removal efficiency, the number of the composite electrodes was set as $1,2,4,6,8$ and 10. Further improvement was carried out with the adjustment of distance between the two electrodes as $0.5,1.0,1.5$ and

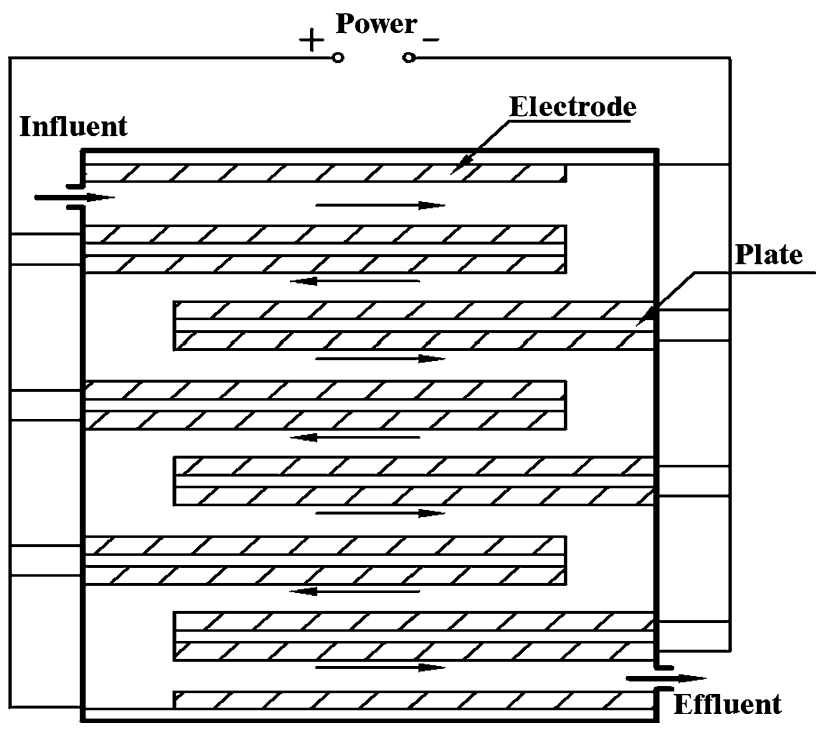

Fig. 1 Design of electrosorption desalination device 
$2.0 \mathrm{~cm}$. To evaluate the energy consumption during the electrosorption process, the electrosorption desalination device was operated for $1 \mathrm{~h}$ with the $1.6 \mathrm{~V}$ operation voltage. During the desalination process, the initial chloride concentration was $1000 \mathrm{mg} / \mathrm{L}$ and the hydraulic retention time was $60 \mathrm{~min}$.

\section{Wastewater treatment}

For the operation voltage optimization, artificial wastewater with $5000 \mathrm{mg} / \mathrm{L} \mathrm{NaCl}$ was applied and the voltages were set as 1.2, 1.4, 1.6, 1.8 and $2.0 \mathrm{~V}$. Throughout the experiment, all the wastewater treatments were undertaken for $1 \mathrm{~h}$. The $\mathrm{pH}$ value of artificial wastewater was adjusted to $2,4,6,8$ and 10 , with separate addition of $20 \% \mathrm{H}_{2} \mathrm{SO}_{4}$ and $30 \% \mathrm{NaOH}$.

\section{Analytical method}

The existence and behavior of functional groups on the graphite and activated carbon fiber composite electrodes were measured and analyzed by Fourier transform infrared spectroscopy (FTIR). The surface structure of the electrode was analyzed by ISM-6700F (JEOL Limited, Japan), and the operation voltage was $10 \mathrm{kV}$. An ASAP2000 automatic adsorption system (Micromeritics, USA) was used to determine the specific surface area, pore volume and pore size of the graphite and activated carbon fiber composite electrodes. With $\mathrm{N}_{2}$ gas as the adsorbent and 12-h completed adsorption-desorption at $77 \mathrm{~K}$, the BET method calculated the specific surface from the sorption isotherm, and the pore volume and pore size were predicted by the density functional formalism (DFF). The cyclic voltammetry of the graphite and activated carbon fiber composite electrodes was measured by $\mathrm{CHI} 660 \mathrm{C}$ electrochemical workstation (CH Instrument, USA) with $10 \mathrm{mV} / \mathrm{s}$ scan rate.

Chemical oxygen demand $\left(\mathrm{COD}_{\mathrm{Cr}}\right)$ followed fast digestion-spectrophotometric method, and analyzed by COD analyzer (DR 2700, Hach, USA). COD was determined according to APHA standard methods (APHA 2005). The $2.0 \mathrm{~mL}$ water sample was mixed and digested with $1.0 \mathrm{~mL}$ digestion solution $\left(10.22 \mathrm{~g} / \mathrm{L} \mathrm{K}_{2} \mathrm{Cr}_{2} \mathrm{O}_{7}, 67 \mathrm{~mL} / \mathrm{L} \mathrm{H}_{2} \mathrm{SO}_{4}\right.$ and $33.3 \mathrm{~g} / \mathrm{L} \mathrm{HgSO}_{4}$ ) at $150{ }^{\circ} \mathrm{C}$ for $2 \mathrm{~h}$ in DR4000 digester (Hach, USA). The solution was then cooled down and measured at $420 \mathrm{~nm}$ with UV2501PC spectrophotometer (SHIMADZU, Japan). The $425 \mathrm{mg}$ potassium hydrogen phthalate was dissolved in $1.0 \mathrm{~L}$ deionized water and series diluted as standard COD solution with COD concentrations of $500,100,50,10,5$ and $1 \mathrm{mg} / \mathrm{L}$. The chloride measurement followed silver nitrate titration method (Chinese EPA 2002). The $\mathrm{pH}$ value was determined by $\mathrm{pH}$ meter (PHS-2, Xi' an Yima Opto-electrical Technology, China). The biodegradability of wastewater after electrosorption was evaluated by the specific oxygen uptake rate, and the dissolved oxygen (DO) in wastewater sample was measured with a fluorescent DO meter (HQ30d, Hach, USA).

\section{Results and discussion}

\section{Surface structure analysis of graphite and activated carbon fiber composite electrodes}

The KOH-treated electrode had significantly different morphological structure with different treatment temperatures, as shown in Fig. 2. The electrode surface was smooth with low specific surface area (Fig. 2a) before any treatment, and the adsorption is not of high efficiency. Different from the acid treatment effects on the mesoporous carbon ( $\mathrm{Li}$ et al. 2006), no clear and ordered carbon structure was observed on the electrode surface. The adsorption capacity was improved by increasing surface area with $\mathrm{KOH}$ alkaline treatment. Figure $2 \mathrm{~b}-\mathrm{d}$ illustrated that the electrode surface had more porous microstructure with the increasing $\mathrm{KOH}$ treatment temperature. Further, pore structure (Table S1) proved the increasing BET specific surface area from $1050.3 \mathrm{~m}^{2} / \mathrm{g}$ (original activated carbon fiber before treatment) to $1263.6-1367.4 \mathrm{~m}^{2} / \mathrm{g}$ (KOH treatment under different temperatures), and $850{ }^{\circ} \mathrm{C}$ treatment has the highest value. The pore volume and size also increased from $1.165 \mathrm{~cm}^{3} / \mathrm{g}$ and $1.88 \mathrm{~nm}$ (original activated carbon fiber before treatment) to $1.337 \mathrm{~cm}^{3} / \mathrm{g}$ and $1.99 \mathrm{~nm}\left(850^{\circ} \mathrm{C} \mathrm{KOH}\right.$ treatment). Similar to the previous study (Bleda-Martinez et al. 2006), the $\mathrm{KOH}$ activation caused certain structural rearrangement on the carbon surface and the temperature was the restriction factor affecting the activation process. More evidence from infrared spectrum also showed stronger stretching vibration of hydroxyl $\left(-\mathrm{OH}, 3440 \mathrm{~cm}^{-1}\right)$, carbonyl $\left(\mathrm{C}=\mathrm{O}, 1650 \mathrm{~cm}^{-1}\right)$ and carboxyl (-COOR, $1200 \mathrm{~cm}^{-1}$ ) after $\mathrm{KOH}$ treatment (Zhou et al. 2014), indicating higher ion exchange ability to improve the ion adsorption capacities of the composite electrodes. Furthermore, the carbonyl group also had the characteristics to accelerate the electron transfer and the desalting efficiency of the composite electrodes might be further enhanced. Compared to nanostructures of other carbon materials, the surface morphologies illustrated that $\mathrm{KOH}$ treatment effectively improves the porosity of the graphite and activated carbon fiber (Bleda-Martinez et al. 2006), with higher surface area than carbon cloth (Ahn et al. 2007) or direct active carbon coating electrode (Choi and Choi 2010). Nevertheless, the graphite treatment increased the pore size and decreased the number of pores smaller than $1 \mathrm{~nm}$, which might negatively affect the desalination efficiency due to the positive relationship between desalination and the volume of pores $<1 \mathrm{~nm}$ (Porada 

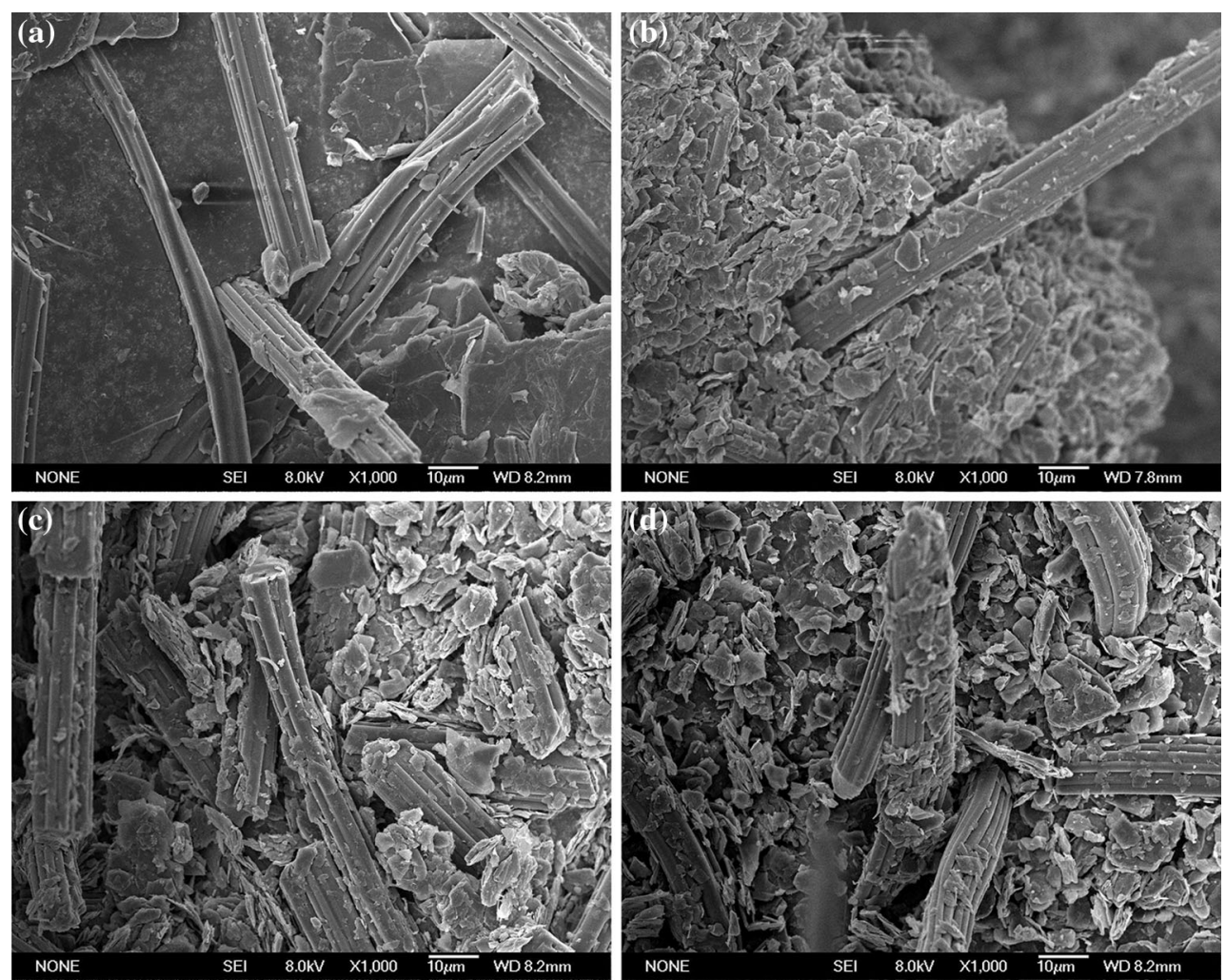

Fig. 2 SEM images of electrode surface with different $\mathrm{KOH}$ treatment. a no $\mathrm{KOH}$ treatment; b $\mathrm{KOH}$ treatment at $750{ }^{\circ} \mathrm{C}$ for $1 \mathrm{~h}$; $\mathbf{c} \mathrm{KOH}$ treatment at $850{ }^{\circ} \mathrm{C}$ for $1 \mathrm{~h}$; $\mathbf{d ~ K O H}$ treatment at $950{ }^{\circ} \mathrm{C}$ for $1 \mathrm{~h}$

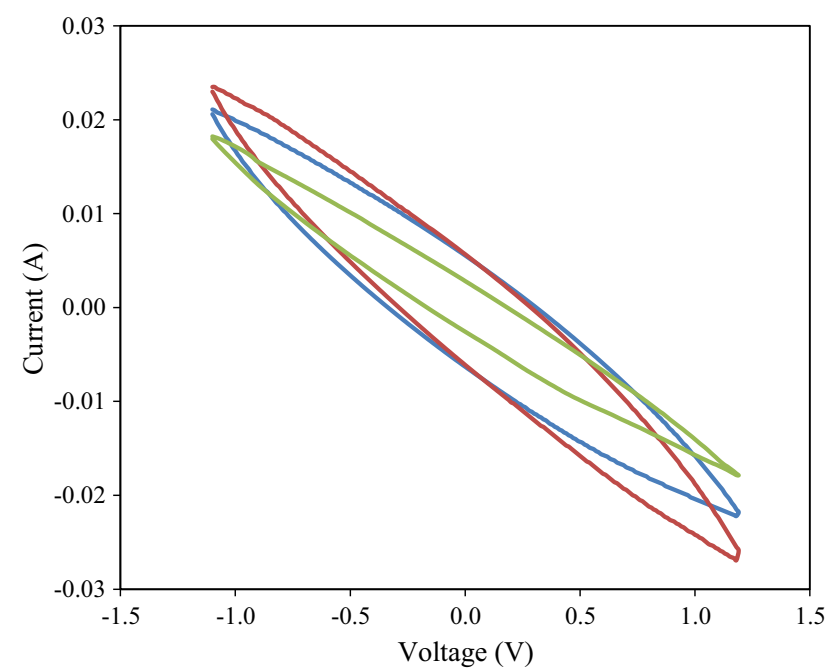

$-750^{\circ} \mathrm{C}$ treatment $-850^{\circ} \mathrm{C}$ treatment $-950^{\circ} \mathrm{C}$ treatment

Fig. 3 Cyclic voltammetry of the graphite and activated carbon fiber composite electrodes under different treatment temperature

et al. 2013a). Figure 3 illustrates the cyclic voltammetry of the graphite and activated carbon fiber composite electrodes, and each $\mathrm{C}-\mathrm{V}$ curve has a smooth increasing and declining pattern, suggesting the reversible desalination process. There was no obvious peak current, showing no oxidation- reduction reaction during the electrosorption process. Determined by other two variables as chemical impregnation ratio and activation time (Hameed et al. 2008), the optimal $\mathrm{KOH}$ treatment condition was evaluated as $850{ }^{\circ} \mathrm{C}, 1 \mathrm{~mol} / \mathrm{L}$ and $1 \mathrm{~h}$ for the highest desalination and organic pollutants removal efficiency. The results of cyclic voltammetry also revealed that the composite electrode with $850{ }^{\circ} \mathrm{C} \mathrm{KOH}$ treatment has the highest current capacity.

\section{Restriction factors of electrosorption treatment for artificial wastewater}

\section{Initial chloride concentration}

Negative relationship was observed between chloride initial concentration and its removal efficiency, as shown in Fig. 4. The removal efficiency dropped dramatically from $64 \%(100 \mathrm{mg} / \mathrm{L})$ to $15 \%(20,000 \mathrm{mg} / \mathrm{L})$ in artificial salinity wastewater samples. However, the total amount of chloride removal increased with the initial chloride concentration, which was from $36 \mathrm{mg} / \mathrm{L}$ (initial concentration $100 \mathrm{mg} / \mathrm{L}$ ) to $3000 \mathrm{mg} / \mathrm{L}$ (initial concentration $20,000 \mathrm{mg} /$ L). The adsorption isotherms were simulated by linearized Langmuir equation (Eq. 1) and Freundlich equation (Eq. 2). 
$Q=Q_{\max } \frac{K_{\mathrm{L}} C}{1+K_{\mathrm{L}} C}$

$Q=K_{\mathrm{F}} C^{1 / n}$

Here, $Q$ represents the chloride equilibrium concentration $(\mathrm{mg} / \mathrm{L})$ and $C$ is the mount of adsorbed chloride ion on the carbon electrode $(\mathrm{mg} / \mathrm{g}) . Q_{\max }$ is the maximum adsorption capacity in accordance with the complete monolayer coverage. $K_{\mathrm{L}}$ is Langmuir constant $(\mathrm{L} / \mathrm{mg})$ determined by binding energy, whereas $K_{\mathrm{F}}$ and $n$ are the Freundlich constants referring to the adsorption capacity and the absorption tendency, respectively. As simulated in Fig. 4 and Table 1, both isotherms models match the experimental data with high regression coefficient (Supplementary material Fig. S1 and S2). Freundlich isotherms predicted the behavior of $\mathrm{NaCl}$ adsorption more accurately than the Langmuir model. Of different isotherm dynamics investigated previously (Ban et al. 1998; Hoda et al. 2006; Hou et al. 2013; Li et al. 2009), Langmuir isotherms fitted with

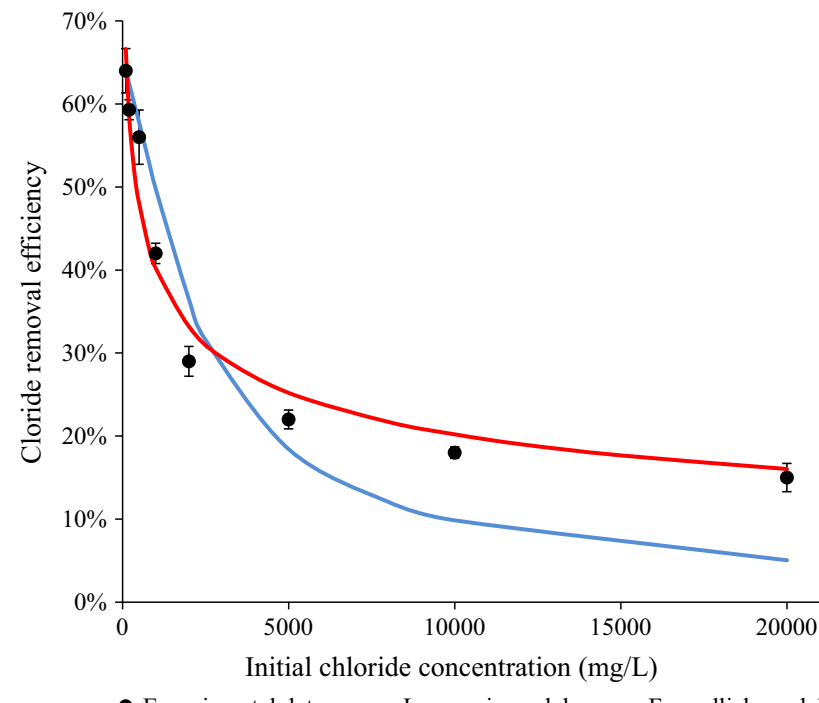

Fig. 4 Impacts of initial chloride concentration on desalination efficiency (black dots) and isotherm model simulation (Langmuir and Freundlich, red and blue line) for chloride adsorption on the composite electrode

Table 1 Determined parameters of $K_{\mathrm{L}}, K_{\mathrm{F}}$ and $\mathrm{n}$ of Langmuir and Freundlich isotherms model

\begin{tabular}{llll}
\hline Isotherm & Model equation & Parameter & Value \\
\hline Langmuir & $Q=Q_{\max } \frac{K_{\mathrm{L}} C}{1+K_{\mathrm{L} C}}$ & $Q_{\max }$ & 1.89 \\
& & $K_{\mathrm{L}}$ & 0.544 \\
& $R^{2}$ & 0.9850 \\
Freundlich & $Q=K_{\mathrm{F}} C^{1 / n}$ & $K_{\mathrm{F}}$ & 7.56 \\
& & $1 / n$ & 0.622 \\
& & $R^{2}$ & 0.9882
\end{tabular}

the desalination behavior well when the initial $\mathrm{NaCl}$ concentration was low (Wang et al. 2012), whereas Freundlich isotherms interpreted better behavior under high salt conditions (Ayranci and Hoda 2005; Li et al. 2010). Table 1 also demonstrates that the $1 / n$ value $(0.622)$ was between 0.1 and 1 , indicating the favorable adsorption process on the surface of fiber composite electrodes.

\section{Operation voltage}

Figure 5 illustrates the conductivity removal curve, and the absorption equilibrium was observed after $60 \mathrm{~min}$ when the removal efficiency became constant. The final conductivity removal efficiency was $29 \%$ when the operation voltage was $1.2 \mathrm{~V}$, and the adsorption capacity gradually increased with the operation voltage. With limited electrolysis reaction when the voltage was below $1.8 \mathrm{~V}$, the highest conductivity removal efficiency was $55 \%(1.8 \mathrm{~V})$.

Adsorption kinetics of $\mathrm{NaCl}$ is important for the desalination process, and the operation voltage significantly affects the adsorption dynamics. The kinetics of electrosorption under different operation voltage $(1.2,1.4,1.6$, 1.8 and $2.0 \mathrm{~V}$ ) was determined and simulated by the pseudo-first-order adsorption process (Wang et al. 2012), as shown in the following Eqs. (3) and (4).

$\frac{\mathrm{d} C}{\mathrm{~d} t}=-k\left(C-C_{\mathrm{e}}\right)$

$\log \left(C-C_{\mathrm{e}}\right)=\log \left(C_{0}-C_{\mathrm{e}}\right)-\frac{k}{2.303} \cdot t$

where $t$ is the reaction time $(\min )$ and $k$ refers to the adsorption rate constant $\left(\mathrm{min}^{-1}\right) . C$ is the dynamic $\mathrm{NaCl}$

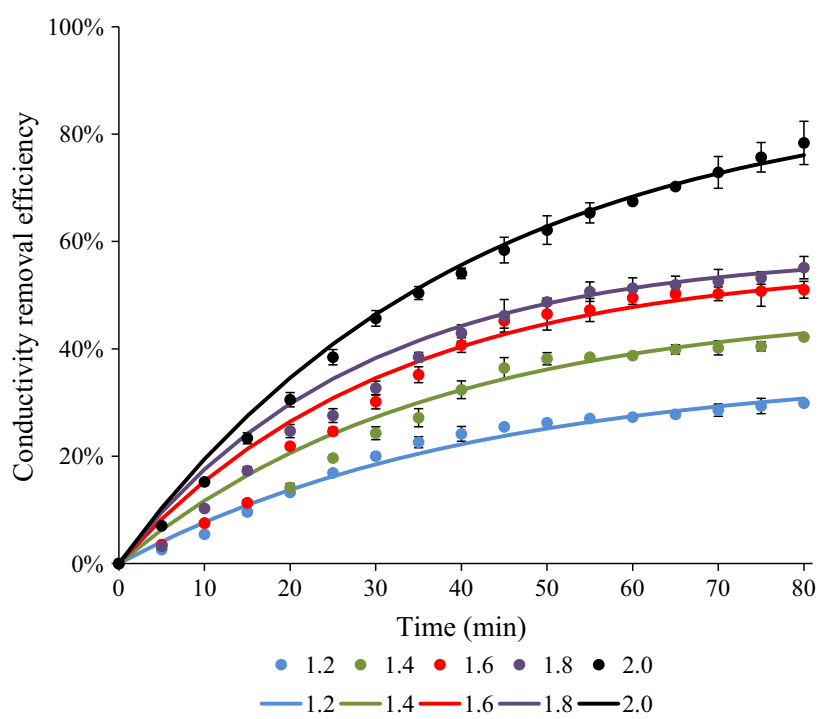

Fig. 5 Desalination performance at different operation voltages (dot) and Freundlich isotherm dynamic simulation (line) for ion adsorption on the composite electrode 
concentration $(\mathrm{mg} / \mathrm{L})$, whereas $C_{0}$ and $C_{\mathrm{e}}$ represent the initial and equilibrium concentration of $\mathrm{NaCl}(\mathrm{mg} / \mathrm{L})$, respectively. Table 2 lists the values of adsorption rate constant and equilibrium $\mathrm{NaCl}$ concentration. It was obvious that $C_{\mathrm{e}}$ has positive relationship with the increase in operation voltage, whereas $k$ reached the maximal value of 0.036 when operation voltage was $1.8 \mathrm{~V}$ and dropped at $2.0 \mathrm{~V}$. This phenomenon was caused by the electrolysis of sodium chloride occurring at high operation voltage as stated previously (Cho et al. 2010), consequently resulting in dramatic conductivity removal efficiency jumped to $78 \%$. Considering the energy consumption and operation safety, the optimal operation voltage was suggested as $1.6 \mathrm{~V}$ and applied in further experiments.

\section{pH value}

As illustrated in Fig. 6, pH had limited impacts on the desalting performance. Chloride removal efficiency dropped slightly with the increase in $\mathrm{pH}$ value. The electrostatic repulsion on the surface of composite electrodes led to a larger amount of positive charges at low $\mathrm{pH}$ (Ayranci and Duman 2005), causing higher desalination efficiency to some extent. Though $\mathrm{pH}$ was observed as sensitive parameters for fluoride electrosorption removal (Lounici et al. 1997), chloride had higher ion strength and was only slightly affected by the hydroxide ion during the electrosorption process. $\mathrm{pH}$ was not the restriction factor for the desalination efficiency of industrial wastewater with high sodium chloride concentration.

\section{Electrode distance}

Electrode distance showed unique impacts on chloride removal efficiency (Fig. 7a). The highest chloride removal efficiency (48\%) was achieved when the electrode distance was $1.0 \mathrm{~cm}$. When the distance was too small $(0.5 \mathrm{~cm})$, the high flow rate led to shorter contact time between the wastewater and the electrode, consequently resulting in insufficient adsorption, though the shorter distance could improve the capacity of electrical adsorption.

Based on the pseudo-first-order adsorption process demonstrated in Eqs. (3) and (4), the adsorption rate constant per unit volume of fluid $\left(k^{\prime}\right.$, where $\left.k=\frac{w \cdot l \cdot d}{v_{i}} \cdot k^{\prime}\right)$ was introduced to evaluate the integral impacts of electrode distance and flow rate, and the following Eq. (5) shows the modified electrosorption dynamics. $\log \left(C-C_{\mathrm{e}}\right)=\log \left(C_{0}-C_{\mathrm{e}}\right)-\frac{w \cdot l}{2.303 \times v_{i}} \cdot k^{\prime} \cdot d$

Here, $w, l$ and $d$ represent the width $(\mathrm{cm})$, length $(\mathrm{cm})$ and distance $(\mathrm{cm})$ of the electrodes. $v_{i}$ is the influent flow rate $\left(\mathrm{cm}^{3} / \mathrm{min}\right)$. The adsorption rate constant per unit area, $k^{\prime}$, changes with the electrode distance $(d)$. Electrodes with the same length and width but shorter distance have higher electrocapacities (Porada et al. 2013b), consequently leading to higher adsorption rate constant. The model simulation also fitted with the experimental results when the electrode distance was above $1.0 \mathrm{~cm}$ (Fig. 7b). The decreasing electronic force had superiority to the increasing contact time, and the optimal electrode distance was therefore suggested as $1.0 \mathrm{~cm}$. Though electrical double layer has suggested smaller distance for higher capacitance (Simon and Gogotsi 2008), the conclusion in this work gives more evidence on the desalination efficiency with variable distance and flow velocity determined by constant flow rate.

\section{Regeneration and energy consumption}

With initial $1000 \mathrm{mg} / \mathrm{L}$ sodium chloride as the influent, the desalination performance of the graphite and activated carbon fiber composite electrodes after regeneration was evaluated (Fig. S3). The electrosorption efficiency was initially $77.9 \%$ and maintained from 77.7 to $78.0 \%$ within

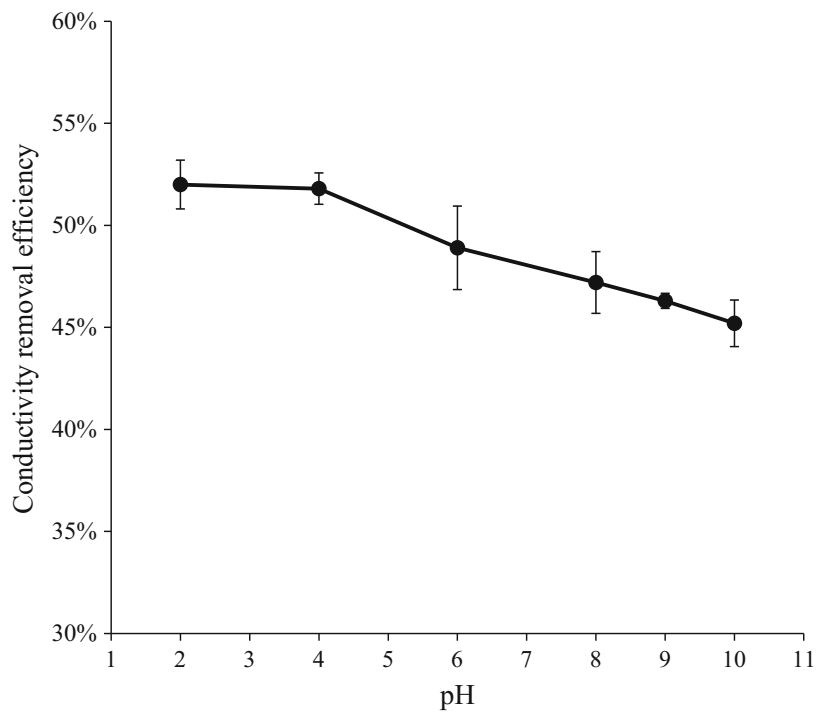

Fig. 6 Desalination efficiency against $\mathrm{pH}$ value
Table 2 Adsorption rate constant and equilibrium $\mathrm{NaCl}$ concentration under different operation voltages

\begin{tabular}{llllll}
\hline Voltage $(\mathrm{V})$ & 1.2 & 1.4 & 1.6 & 1.8 & 2.0 \\
\hline$k$ & 0.024 & 0.028 & 0.032 & 0.036 & 0.025 \\
$C_{\mathrm{e}}(\mathrm{mg} / \mathrm{L})$ & 1800 & 2400 & 2800 & 2900 & 4400 \\
\hline
\end{tabular}



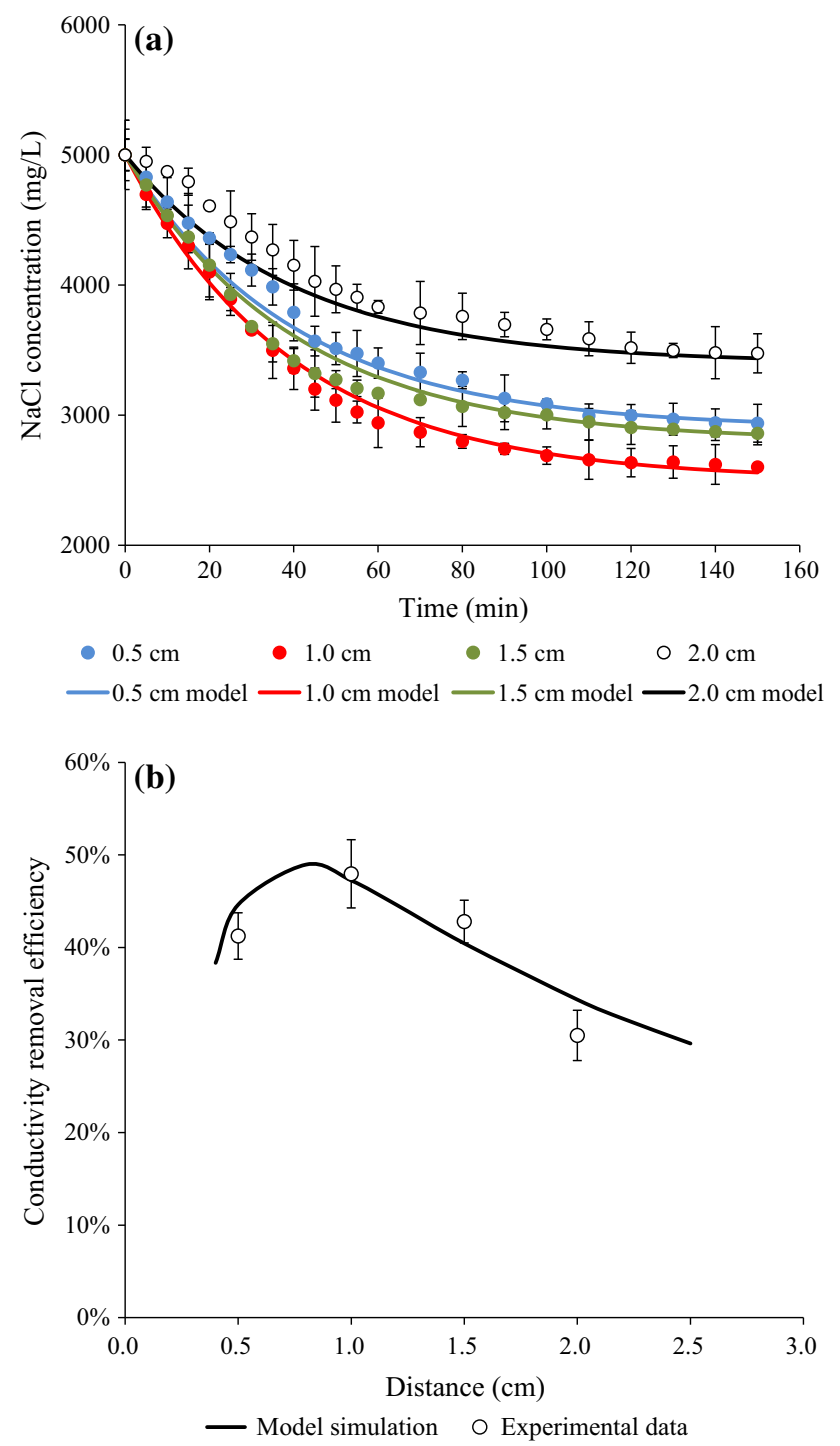

Fig. 7 Desalination performance with different electrode distances (dot) and Freundlich isotherm dynamic simulation (line) for ion adsorption on the composite electrode (a). The isotherm model demonstrated the impacts of electrode distance on desalination efficiency (b)

10 cycles of regeneration. After 20 cycles of regeneration, the desalination performance still maintained over $77.0 \%$, showing the stability of the composite electrodes in engineering application. From the results of energy consumption during electrosorption process, the operation current was $6.7 \mathrm{~mA}(1.6 \mathrm{~V}$ operation voltages) and the energy consumption was $0.538 \mathrm{kWh} / \mathrm{m}^{3}$ when initial chloride concentration was $1000 \mathrm{mg} / \mathrm{L}$ and the hydraulic retention time was $60 \mathrm{~min}$. Compared to the energy consumption from 1.06 to $1.80 \mathrm{kWh} / \mathrm{m}^{3}$ by reverse osmosis treatment (Elimelech and Phillip 2011), the graphite and activated carbon fiber composite electrodes in this study had the advantages in energy saving. However, this work was only

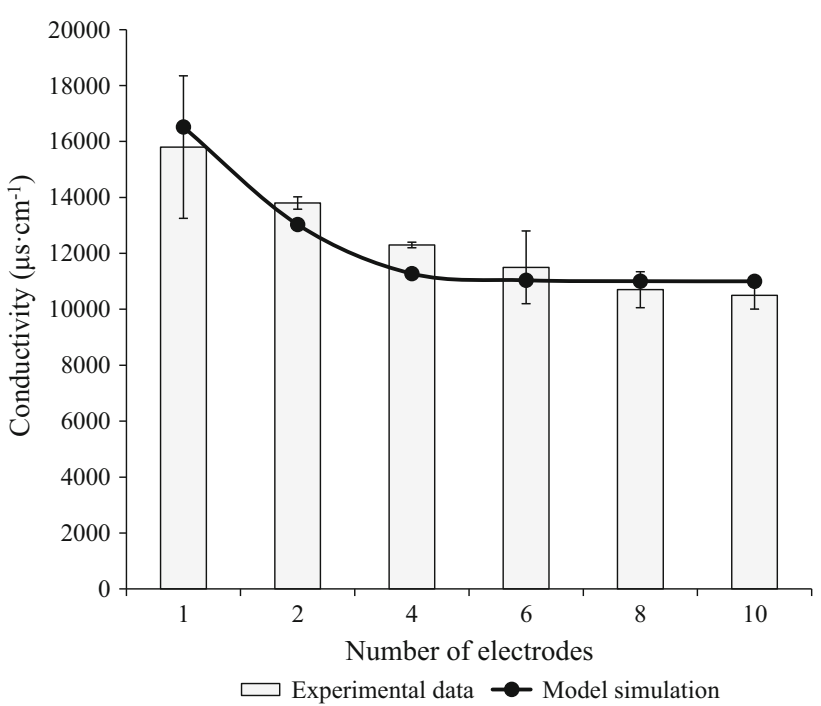

Fig. 8 Experimental conductivity removal efficiency (column) and Freundlich isotherm simulation (dot and line) of refined cotton wastewater by electrosorption desalination

conducted in small scale and its practical energy consumption needed further investigation.

\section{Performance of electrosorption treatment for real salinity wastewater}

\section{Black liquor from refined cotton wastewater}

After acidification, the $\mathrm{COD}_{\mathrm{Cr}}$ and conductivity of black liquor from refined cotton wastewater were $8040 \mathrm{mg} / \mathrm{L}$ and $26,000 \mu \mathrm{s} / \mathrm{cm}$, respectively. Under optimal operation condition obtained above, the $\mathrm{COD}_{\mathrm{Cr}}$ and conductivity removal are shown in Fig. 8. More removal efficiency was achieved with higher number of composite electrodes, and the highest removal efficiency for conductivity and $\mathrm{COD}_{\mathrm{Cr}}$ was achieved when the number of electrodes was 10 . The $\mathrm{COD}_{\mathrm{Cr}}$ removal could be explained by the adsorption of electronic charged organic molecules in the black liquor of refined cotton wastewater, with similar mechanisms as chloride ion.

Regarding the positive relationship between the increasing number of electrodes and the contacting distance for the influent (Porada et al. 2012), the electrosorption kinetic was expressed in Eq. (6), where $n$ represented the number of electrodes.

$\log \left(C-C_{\mathrm{e}}\right)=\log \left(C_{0}-C_{\mathrm{e}}\right)-\frac{d \cdot w \cdot l \cdot k}{2.303 \times V} \cdot n$

Dynamic model simulation successfully predicted the behavior of conductivity removal with different number of electrodes (Fig. 8). As the determinant factor, more electrodes improved the high-salinity wastewater 
treatment performance in terms of longer electrosorption contact time. The impacts were significant when the number of electrodes was less than 4 , where the conductivity removal efficiency increased significantly from 39 to $53 \%$. When the number of electrodes was higher, the increase in removal efficiency dropped. Taking both efficiency and cost into account, the suggested number of electrodes was eight and the conductivity and $\mathrm{COD}_{\mathrm{Cr}}$ removal efficiency was 59 and $76 \%$, respectively.

The significant improvement in oxygen consumption rate, from $0.090 \mathrm{mg} /(\mathrm{L} \mathrm{min})$ to $0.381 \mathrm{mg} /(\mathrm{L} \mathrm{min})$, was also observed after the electrosorption treatment (Zhou et al. 2014). Due to the inhibition effects of salinity on the growth and activities of microbes, the electrosorption treatment could encourage the biodegradation capacity through salinity mitigation (Fan et al. 2006). Besides, electrosorption treatment might also remove some other macromolecules or toxic chemicals, which further contributed to the biodegradability enhancement (Fan et al. 2008). There was only limited research investigating the biodegradability change after electrosorption treatment (Donnaperna et al. 2009), and only artificial wastewater samples were tested (Fan et al. 2006). From the six possible electrochemical effects on the electrode surface for organic matter removal, the biodegradability improvement might be explained by the capacitive ion storage in the electrical double layer or Faradaic reactions on the electrode surface (Porada et al. 2013b). The capacitive ion storage could effectively capture the polar organic molecule in the double layer, and the Faradaic reaction could be quinone into hydroquinone, which is easier for biodegradation (Jensen et al. 2002). In this research, the author did not observe the hydroquinone formation or organics polarity change due to the complexity and high concentration of organic molecules in the real black liquor from refined cotton wastewater. The results in study were the first time to prove that the biodegradability of real industry wastewater could be improved by electrosorption treatment, but the main mechanisms required further investigation.

\section{Sodium copper chlorophyll wastewater}

For sodium copper chlorophyll wastewater, the values of $\mathrm{COD}_{\mathrm{Cr}}$ and conductivity in water sample were $6600 \mathrm{mg} / \mathrm{L}$ and $16,250 \mu \mathrm{s} / \mathrm{cm}$, respectively. As illustrated in Fig. 9, different conductivity removal efficiency was achieved in the treatments with respective electrodes numbers. Similar to the results of refined cotton wastewater treatment, higher conductivity removal efficiency was achieved with the increasing number of electrodes. Simulated by the adsorption model, the relationship between the conductivity removal and electrode number is shown in Fig. 9, where the highest

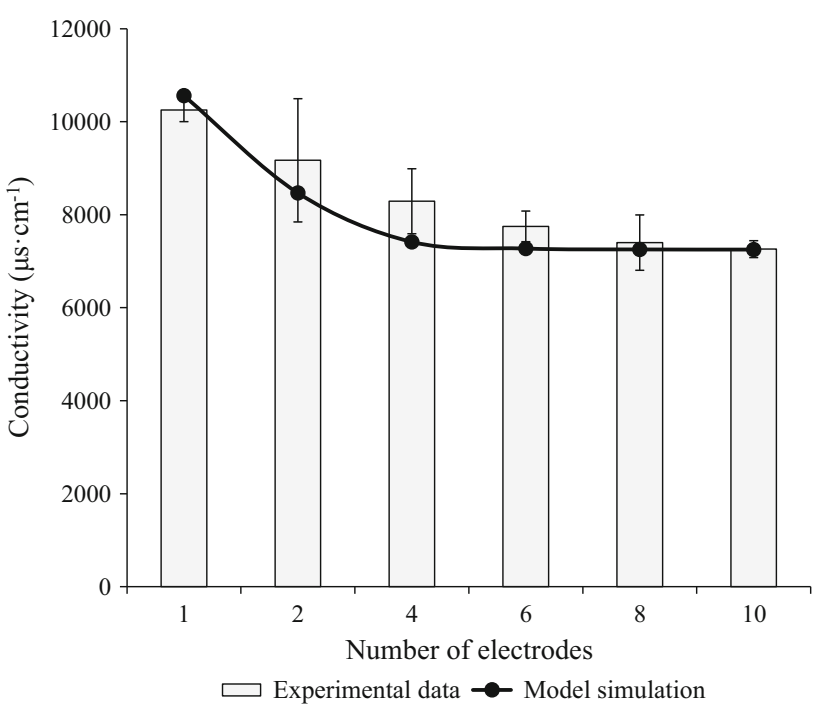

Fig. 9 Experimental conductivity removal efficiency (column) and Freundlich isotherm simulation (dot and line) of sodium copper chlorophyll wastewater by electrosorption desalination

removal efficiency was $37 \%$ when the number of electrodes was 10 . However, $\mathrm{COD}_{\mathrm{Cr}}$ removal had significant change from $11 \%$ (1 pair of electrode) to $14 \%$ (10 pairs of electrodes), possibly due to less charged organic matters in sodium copper chlorophyll wastewater (Ferruzzi and Schwartz 2005). Eight pairs of electrodes were also suggested as the practical operation condition for sodium copper chlorophyll wastewater desalination. It is similar that the biodegradation capacity of the sodium copper chlorophyll wastewater was also improved, in which the oxygen consumption rate after electrosorption was $0.219 \mathrm{mg} /(\mathrm{L} \mathrm{min})$, higher than $0.077 \mathrm{mg} /(\mathrm{L} \mathrm{min})$ in the original wastewater.

\section{Conclusion}

In this study, we optimized the electrosorption desalination device, with the graphite and activated carbon fiber composite electrodes, to improve the treatment efficiency of refined cotton and sodium copper chlorophyll wastewater. The three key identified as factors affecting the salinity and organic matter removal efficiency were retention time, electrode voltage and electrode distance. The optimal condition for desalination was $60 \mathrm{~min}, 1.6 \mathrm{~V}$ and $1.0 \mathrm{~cm}$. pH showed limited impacts on the removal efficiency of chloride and $\mathrm{COD}_{\mathrm{Cr}}$. Compared to Langmuir model, Freundlich isotherms fitted better with the desalination performance of the composite electrodes under respective conditions. With optimal eight pairs of electrodes for practical desalting, this technique successfully achieved high conductivity removal efficiency for 
real refined cotton and sodium copper chlorophyll wastewater. The further improvement in biodegradability also suggested that the graphite and activated carbon fiber composite electrodes have promising application prospects for industrial salinity wastewater treatment as an appropriate pretreatment to encourage advanced biological treatment.

Acknowledgments The authors would like to thank the financial support of the National Science and Technology Department Support Program (2011BAC10B04, Typical Scrap Metal Products Recycling Technology and Application Research).

\section{References}

Ahn H-J, Lee J-H, Jeong Y, Lee J-H, Chi C-S, Oh H-J (2007) Nanostructured carbon cloth electrode for desalination from aqueous solutions. Mater Sci Eng, A 449:841-845

APHA (2005) APHA standard methods (21st edn, Method 5220 D)

Avraham E, Noked M, Cohen I, Soffer A, Aurbach D (2011) The dependence of the desalination performance in capacitive deionization processes on the electrodes PZC. J Electrochem Soc 158(12): 168-173

Ayranci E, Duman O (2005) Adsorption behaviors of some phenolic compounds onto high specific area activated carbon cloth. J Hazard Mater 124(1-3):125-132

Ayranci E, Hoda N (2005) Adsorption kinetics and isotherms of pesticides onto activated carbon-cloth. Chemosphere 60(11):1600-1607

Ban A, Schafer A, Wendt H (1998) Fundamentals of electrosorption on activated carbon for wastewater treatment of industrial effluents. J Appl Electrochem 28(3):227-236

Bleda-Martinez MJ, Lozano-Castello D, Morallon E, Cazorla-Amoros D, Linares-Solano A (2006) Chemical and electrochemical characterization of porous carbon materials. Carbon 44(13):2642-2651

Boening DW (2000) Ecological effects, transport, and fate of mercury: a general review. Chemosphere 40(12):1335-1351

Burkholder JM, Tomasko DA, Touchette BW (2007) Seagrasses and eutrophication. J Exp Mar Biol Ecol 350(1-2):46-72

Cantor KP (1997) Drinking water and cancer. Cancer Causes Control 8(3):292-308

Chang LM, Duan XY, Liu W (2011) Preparation and electrosorption desalination performance of activated carbon electrode with titania. Desalination 270(1-3):285-290

Chen C, Zhang D, Thornton SF, Duan M, Luo Y, Ding A, Huang WE (2013) Functionalization and immobilization of whole cell bioreporters for the detection of environmental contamination. Environ Eng Manag J 12(7):1417-1422

Chinese EPA (ed) (2002) Standard methods for water and wastewater monitoring and analysis

Cho JH, Lee JE, Ra CS (2010) Effects of electric voltage and sodium chloride level on electrolysis of swine wastewater. J Hazard Mater 180(1-3):535-541

Choi J-Y, Choi J-H (2010) A carbon electrode fabricated using a poly(vinylidene fluoride) binder controlled the Faradaic reaction of carbon powder. J Ind Eng Chem 16(3):401-405

Donnaperna L, Duclaux L, Gadiou R, Hirn MP, Merli C, Pietrelli L (2009) Comparison of adsorption of Remazol Black B and Acidol Red on microporous activated carbon felt. J Colloid Interface Sci 339(2):275-284
Elimelech M, Phillip WA (2011) The future of seawater desalination: energy, technology, and the environment. Science 333(6043):712-717

Fan L, Zhou Y, Yang W, Chen G, Yang F (2006) Electrochemical degradation of Amaranth aqueous solution on ACF. J Hazard Mater 137(2):1182-1188

Fan L, Zhou Y, Yang W, Chen G, Yang F (2008) Electrochemical degradation of aqueous solution of Amaranth azo dye on ACF under potentiostatic model. Dyes Pigm 76(2):440-446

Farmer JC, Fix DV, Mack GV, Pekala RW, Poco JF (1995) Capacitive deionization with carbon aerogel electrodes: carbonate, sulfate, and phosphate. 27th International technical conference of the society for the advancement of material and process engineering (SAMPE): diversity into the next century, Albuquerque, NM (United States)

Farmer JC, Fix DV, Mack GV, Pekala RW, Poco JF (1996) Capacitive deionization of $\mathrm{NaCl}$ and $\mathrm{NaNO} 3$ solutions with carbon aerogel electrodes. J Electrochem Soc 143(1):159-169

Ferruzzi MG, Schwartz SJ (2005) Thermal degradation of commercial grade sodium copper chlorophyllin. J Agric Food Chem 53(18):7098-7102

Greenlee LF, Lawler DF, Freeman BD, Marrot B, Moulin P (2009) Reverse osmosis desalination: water sources, technology, and today's challenges. Water Res 43(9):2317-2348

GuetaDahan Y, Yaniv Z, Zilinskas BA, BenHayyim G (1997) Salt and oxidative stress: similar and specific responses and their relation to salt tolerance in Citrus. Planta 203(4):460-469

Hameed BH, Tan IAW, Ahmad AL (2008) Optimization of basic dye removal by oil palm fibre-based activated carbon using response surface methodology. J Hazard Mater 158(2-3):324-332

Hoda N, Bayram E, Ayranci E (2006) Kinetic and equilibrium studies on the removal of acid dyes from aqueous solutions by adsorption onto activated carbon cloth. J Hazard Mater 137(1):344-351

Hou CH, Huang CY, Hu CY (2013) Application of capacitive deionization technology to the removal of sodium chloride from aqueous solutions. Int J Environ Sci Technol 10(4):753-760

Huang GH, Xia J (2001) Barriers to sustainable water-quality management. J Environ Manage 61(1):1-23

Ishikawa M, Sakamoto A, Morita M, Matsuda Y, Ishida K (1996) Effect of treatment of activated carbon fiber cloth electrodes with cold plasma upon performance of electric double-layer capacitors. J Power Sources 60(2):233-238

Jannakoudakis AD, Jannakoudakis PD, Pagalos N, Theodoridou E (1993) Preparation and catalytic efficiency of mixed noble metal catalysts on electrochemically activated carbon-fiber supports. J Appl Electrochem 23(11):1162-1168

Jensen KA, Ryan ZC, Wymelenberg AV, Cullen D, Hammel KE (2002) An NADH : quinone oxidoreductase active during biodegradation by the brown-rot basidiomycete Gloeophyllum trabeum. Appl Environ Microbiol 68(6):2699-2703

Jing G, Wang X, Zhao H (2009) Study on TDS removal from polymer-flooding wastewater in crude oil: extraction by electrodialysis. Desalination 244(1-3):90-96

Kim C (2005) Electrochemical characterization of electrospun activated carbon nanofibres as an electrode in supercapacitors. J Power Source 142(1-2):382-388

Kolpin DW, Furlong ET, Meyer MT, Thurman EM, Zaugg SD, Barber LB, Buxton HT (2002) Pharmaceuticals, hormones, and other organic wastewater contaminants in US streams, 1999-2000: a national reconnaissance. Environ Sci Technol 36(6):1202-1211

Lee J-B, Park K-K, Yoon S-W, Park P-Y, Park K-I, Lee C-W (2009) Desalination performance of a carbon-based composite electrode. Desalination 237(1-3):155-161 
Lefebvre O, Moletta R (2006) Treatment of organic pollution in industrial saline wastewater: a literature review. Water Res 40(20):3671-3682

Li JW, Yu ZB, Gao M, Cai XP (1997) Trihalomethanes adsorption on activated carbon fiber and granular activated carbon. Water Air Soil Pollut 97(3-4):367-378

Li L, Song H, Chen X (2006) Ordered mesoporous carbons from the carbonization of sulfuric-acid-treated silica/triblock copolymer/sucrose composites. Microporous Mesoporous Mater 94(1-3):9-14

Li H, Gao Y, Pan L, Zhang Y, Chen Y, Sun Z (2008) Electrosorptive desalination by carbon nanotubes and nanofibres electrodes and ion-exchange membranes. Water Res 42(20):4923-4928

Li H, Lu T, Pan L, Zhang Y, Sun Z (2009) Electrosorption behavior of graphene in $\mathrm{NaCl}$ solutions. J Mater Chem 19(37):6773-6779

Li H, Zou L, Pan L, Sun Z (2010) Novel graphene-like electrodes for capacitive deionization. Environ Sci Technol 44(22):8692-8697

Lounici H, Addour L, Belhocine D, Grib H, Nicolas S, Bariou B, Mameri N (1997) Study of a new technique for fluoride removal from water. Desalination 114(3):241-251

Mtombeni T, Maree JP, Zvinowanda CM, Asante JKO, Oosthuizen FS, Louw WJ (2013) Evaluation of the performance of a new freeze desalination technology. Int $\mathrm{J}$ Environ Sci Technol 10(3):545-550

Nadakatti S, Tendulkar M, Kadam M (2011) Use of mesoporous conductive carbon black to enhance performance of activated carbon electrodes in capacitive deionization technology. Desalination 268(1-3):182-188

Porada S, Bryjak M, van der Wal A, Biesheuvel PM (2012) Effect of electrode thickness variation on operation of capacitive deionization. Electrochim Acta 75:148-156
Porada S, Borchardt L, Oschatz M, Bryjak M, Atchison JS, Keesman KJ, Kaskel S, Biesheuvel PM, Presser V (2013a) Direct prediction of the desalination performance of porous carbon electrodes for capacitive deionization. Energy Environ Sci 6(12):3700-3712

Porada S, Zhao R, van der Wal A, Presser V, Biesheuvel PM (2013b) Review on the science and technology of water desalination by capacitive deionization. Prog Mater Sci 58(8):1388-1442

Rasines G, Lavela P, Macias C, Haro M, Ania CO, Tirado JL (2012) Electrochemical response of carbon aerogel electrodes in saline water. J Electroanal Chem 671:92-98

Simon P, Gogotsi Y (2008) Materials for electrochemical capacitors. Nat Mater 7(11):845-854

Wang Z, Dou B, Zheng L, Zhang G, Liu Z, Hao Z (2012) Effective desalination by capacitive deionization with functional graphene nanocomposite as novel electrode material. Desalination 299:96-102

Zhang D, Ding A, Cui S, Hu C, Thornton SF, Dou J, Sun Y, Huang WE (2013) Whole cell bioreporter application for rapid detection and evaluation of crude oil spill in seawater caused by Dalian oil tank explosion. Water Res 47(3):1191-1200

Zhao D, Xue J, Li S, Sun H, Zhang Q (2011) Theoretical analyses of thermal and economical aspects of multi-effect distillation desalination dealing with high-salinity wastewater. Desalination 273(2-3):292-298

Zhou G, Wang Z, Wang X, Li W, Li S (2014) Research on treatment of high salt wastewater by the graphite and activated carbon fiber composite electrodes. Huanjing Kexue 35(5):1832-1837 